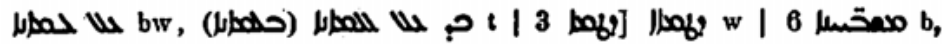
on cum vsu 7 con-

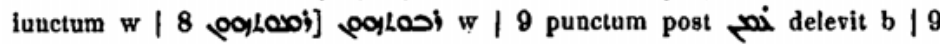

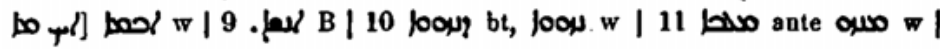

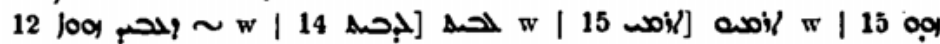

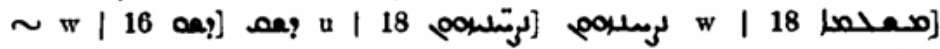

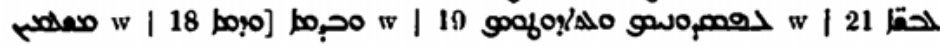

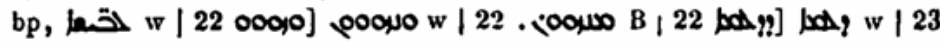

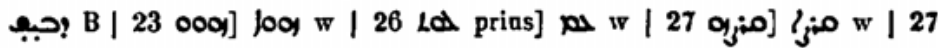

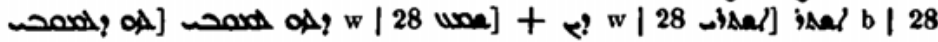

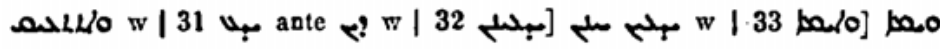

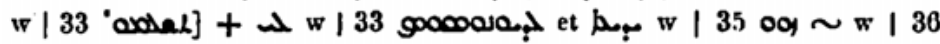

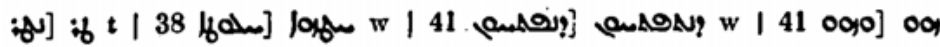

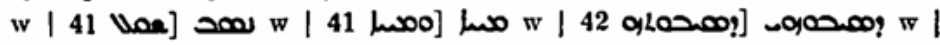

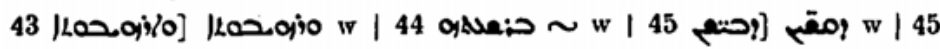

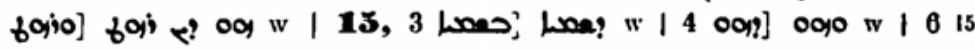

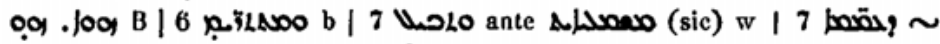

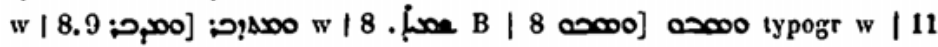

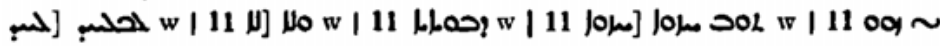

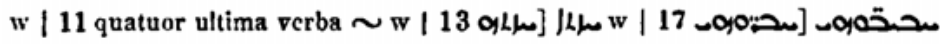

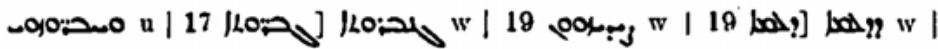

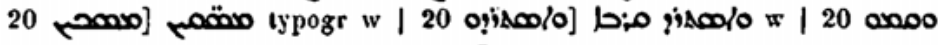

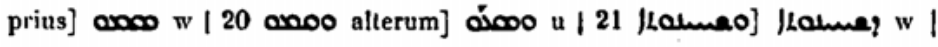

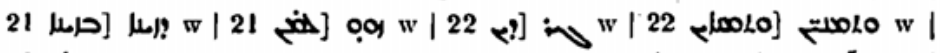

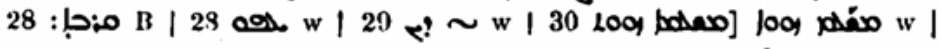

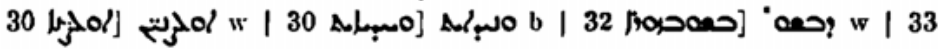
apoo] [achos w I 33 post lacna trium literarum in b | 34

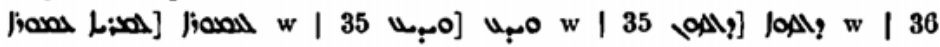

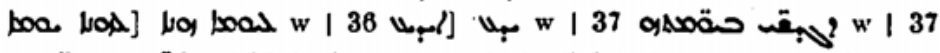

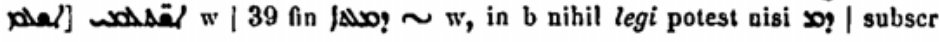

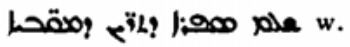

\title{
Maccabaeorum tertius
}

Titulus praem sol w | 1, 3 will L, مده; 1

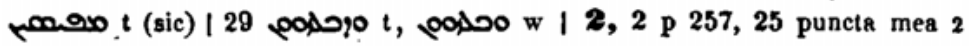

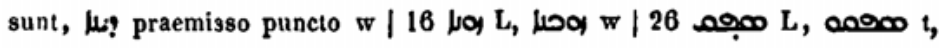

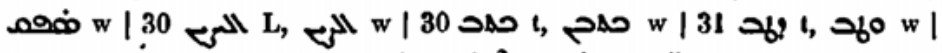

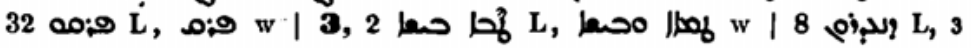

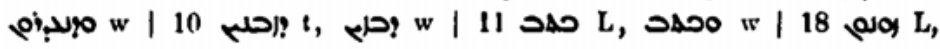




\section{XXxviII}

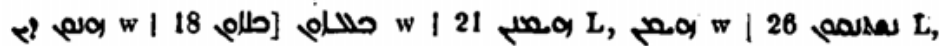

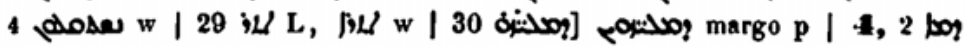

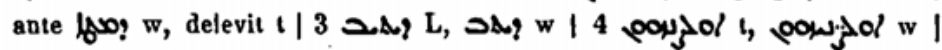

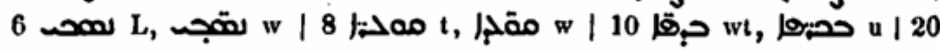

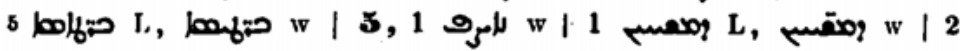

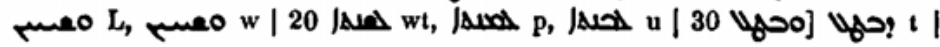

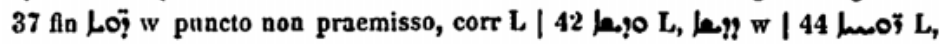

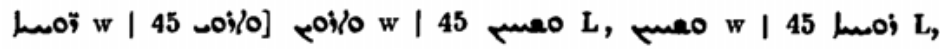

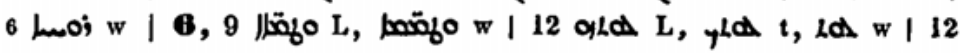

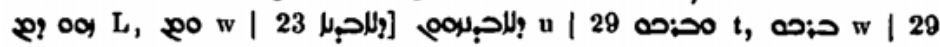

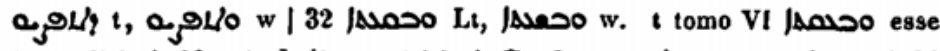

7 in w dicit | 33 ase the $t$ (sic) | 7,7 , 76

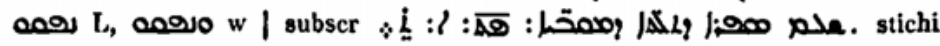
igitur 1400.

Apertos typograpli britannici errores non notavi, quibus adnamero frequens illud 1 Lowo $=$ Lo/bof. Paginae editionis meae $1-16$ impressae sunt ante quam id fieri permisissem, neque numerorum notae ut aequabili magnitndine essent potui impetrare. Corrigenda haec sunt:

Eccles 1, 14 scribe 15

15 dele numerum

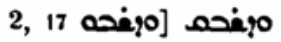

11, موجر 11,27 /Low ${ }^{16}$ ibidem

$12,17, y[3 / 2]+i / 2$

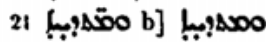

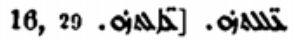

31,22 가

46, 9 0900L] 8900L

48, 19 [حمقا. [1 حمقا.

51, 26 fin .0A] . dA

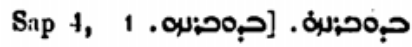

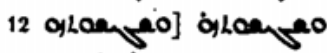

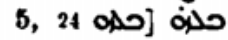

6, 15 . dajik] . Oajik

7,10 व

8, 2 . \%:9001] . 6;:0001.

12, 15 لjog] لjo?

13, 2 الهم:

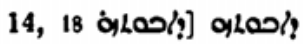

Sap 14, 25 inisosos

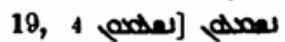

12 oldopali] poy $20^{\circ}$

20 ox [0/0)

Tobit 1, 6 pteitoll] ptertoll

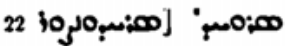

2, 10 ال/

3, 7 , حماحل/

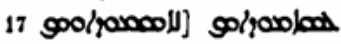

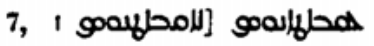

10,

ح:Lات [ح: 12

11, 16 ultimum

12, 19 pal alterum

Baruch $\beta$ 3, 24 moi]

Iudith 2, 28 محر

4, 5 savo]

9, 3 p 116, 1 ante 48

p 125 margo 16, 4-23

Susanna p 136, 12 r.?

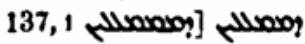


لمسب [لمسبا [asdras 1, 36

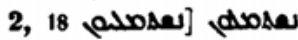

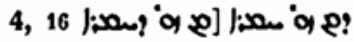

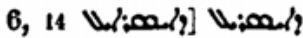

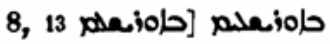
50 0001] loo

p 163 margo $\alpha 1,6-25$

Mace $\alpha$ 5, 35 a

"ער: [20لح: 40

7, 25 ,901] 우어

0, 9 , 이이 y

43 909!] 우?

46 eعمل
Macc $\alpha$ 9, 51 إنقبا

ختبو09ب [نخب:90ب. 55

16, 0

م 2, 11 [مب!.

حقممها. [حفمسمي!. 20

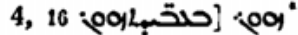

0,1 on: 1 ]

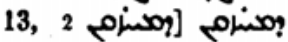

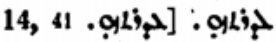

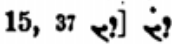

مع [مس

4, 10 /Lanoil] [Anoil

5, 5 "

$\mathrm{Si}$ quae alia erravi, aequns lector condonabit. ego vero, qui per septem annos omne otiun in libros syriacos edendos impenderim, videor mihi iure meo provincia decedere posse.

Berolini id. April. 1881.

Lagarde. 
